\title{
Sleep disturbance, psychiatric issues, and employment status of Iranian people living with HIV
}

\author{
Arezu Najafi ${ }^{1}$, Marzieh Mahboobi ${ }^{2}$, Khosro Sadeghniiat Haghighi' ${ }^{1}$ Faezeh Aghajani ${ }^{3}$, Amin Nakhostin-Ansari ${ }^{4}$, \\ Saber Soltani ${ }^{5,6}$, Ali Jafarpour ${ }^{5,6}$, Parvin Afsar Kazerooni ${ }^{7}$, Matin Bazargani ${ }^{8}$, Somayeh Ghodrati ${ }^{1}$ and \\ Samaneh Akbarpour ${ }^{{ }^{*}}$
}

\begin{abstract}
Objectives: There are limited studies on the psychological issues and sleep problems among the Iranian people living with HIV (HIV). In this study, we aimed to assess sleep disorders, psychiatric characteristics, and employment status among Iranian PLWH.

Results: In total, 304 PLWH with a mean age of $40.01(S D=9.60)$ years participated in the study. About $72 \%$ of the participants had a global PSQI score of more than 5, with a mean score of 7.71 (SD =3.31). About $55.6 \%, 50 \%$, and $67.4 \%$ of subjects had abnormal scores for depression, anxiety, and stress. Unemployed participants had 2.13 times more chance $(95 \% \mathrm{Cl} 1.01-4.53)$ of having poor sleep quality compared to employed patients, and stress increased its likelihood by 3.18 times (95\% Cl 1.47-5.88).
\end{abstract}

Keywords: Sleep quality, Psychiatric issues, Employment, HIV

\section{Introduction}

HIV/AIDS has been a major health problem in recent decades, with a heavy burden on the countries' health systems [1]. Advances in the treatment and management of HIV infection and its aftermath have resulted in increased survival rates for people living with HIV (PLWH), thereby enhancing their quality of life [2]. Over half of HIV-positive people suffer from depression, mania, psychosis, anxiety, and commit suicide. As the disease progresses, physical symptoms such as diarrhea, pain, cough, fever, night sweats, and shortness of breath affect sleep quality. Depression and anxiety are worsened by sleep disturbances, as are the overall quality of life and health [2-4]. Sleep deprivation can also lead to attention

\footnotetext{
*Correspondence: S-akbarpour@sina.tums.ac.ir

${ }^{1}$ Occupational Sleep Research Center, Baharloo Hospital, Tehran

University of Medical Sciences, Tehran, Islamic Republic of Iran

Full list of author information is available at the end of the article
}

deficit disorder, mood swings, fatigue, and cardiovascular complications. In addition, insomnia can reduce treatment response rates, increase disease recurrence and lead to depression [5].

There is evidence that psychological issues are associated with sleep disorders in the general population, but few studies have specifically examined this issue in PLWH. It may be helpful to screen PLWH, as part of routine care, to prevent the progression and side effects of sleep disorders. Therefore, the present study aimed to assess sleep disorders and their associated psychological and socio-economics factors among PLWH.

\section{Main text}

\section{Materials and methods}

A cross-sectional study was conducted between October and November 2019 on 304 PLWH referred to voluntary counseling and testing (VCT) centers in Tehran. A list of the VCT centers from each area of Tehran was compiled, 
and two were picked at random from each area. In each center, patients were randomly selected and invited to participate in the study. The inclusion criteria were HIV diagnosis, age 18 and older, and giving consent to participate in the study. The study protocol was reviewed and approved by the ethics committee of Tehran University of Medical Sciences (IR.TUMS.VCR.REC.1398.312).

In this study, we used the Pittsburgh Sleep Quality Index (PSQI) and Depression Anxiety Stress Scales (DASS). Six psychologists conducted face-to-face interviews with participants to fill out the questionnaires. The Persian version of PSQI measures sleep quality over the past month, and various studies have confirmed its validity and reliability [6-10]. A total of seven subscales are included in the questionnaire, including (1) sleep duration, (2) sleep disturbance, (3) sleep latency, (4) daytime dysfunction due to sleepiness, (5) sleep efficiency, (6) overall sleep quality, and (7) sleep medication use. Each question can be answered on a Likert scale from 0 to 3 , and the total score is calculated from 0 to 21 . A total score greater than five indicates poor sleep quality [11].

DASS has three self-reporting scales to assess negative emotional states, including depression, anxiety, and stress. We used the validated Persian translation of the abbreviated version of DASS, consisting of 21 questions, on a Likert scale from 0 to 3 with higher scores indicating more severe depression, anxiety, and stress [12-14].

We also collected patients' demographic characteristics and medical history, including gender, age, educational level, marital status, history of heart disease, lung diseases, or diabetes, body mass index (BMI), employment status, CD4 count, and co-infection with hepatitis B, C, and tuberculosis. Participants were divided into three groups based on their BMI (less than 25, 25 to 29, and 30 or higher). Employment status was categorized as employed and unemployed. Patients' last measured CD4 was also recorded.

\section{Statistical analysis}

There were 14 participants whose PSQI and DASS questionnaires were incomplete and were excluded from the sample. Other missing values (3.11\%) were imputed using a single imputation method in $\mathrm{R}$ software. We calculated mean and standard deviation (SD) for quantitative variables and frequency and percentage for qualitative variables. A Chi-square test was used to compare qualitative variables, and a T-test was used to compare continuous variables between groups. The logistic Regression model test was used to determine the factors affecting sleep quality. Associations were examined by using the odds ratio and 95\% confidence interval. We calculated crude odds ratios for variables, and entered all variables in the model to calculate the adjusted odds ratios. All analyzes were performed with STATA software, and a P-value of less than 0.05 was considered statistically significant.

\section{Results}

In total, 304 PLWH, including 209 men (68.8\%) and 95 women (31.2\%) with a mean age of 40.01 years, participated in the study. Based on the results of PSQI, 72\% of patients had poor sleep quality. Table 1 shows the association between the sleep quality of participants and their demographic characteristics. Although $70 \%$ of people with poor sleep quality were men, this difference was not statistically significant. A comparison of other demographic characteristics between the two groups of patients with poor sleep quality and good sleep quality showed that the only significant difference was in their job status, as about $85 \%$ of the participants with good sleep quality were employed.

Table 2 shows the association between sleep quality and psychological issues, including stress, anxiety, and depression. The mean PSQI index in participants was 7.71. Among participants, $44 \%$ did not have depression at all, while $56 \%$ suffered from varying degrees of depression, of which $18 \%$ had severe depression. Half of the participants did not suffer from anxiety, and about $20 \%$ suffered from very severe anxiety. Also, about $72 \%$ of participants with good sleep quality did not have anxiety. About $33 \%$ of participants did not have stress, and 11.2\% had very severe stress. About $31 \%$ of participants with poor sleep quality suffered from mild levels of stress.

Table 3 shows the factors affecting sleep quality in our participants, with only stress and employment status affected the quality of sleep independently. Unemployed patients had a 2.13 times more chance $(95 \% \mathrm{CI}$ 1.01-4.53) of having poor sleep quality than employed patients. Patients' stress scale score was also associated with their sleep quality $(\mathrm{OR}=3.18,95 \% \mathrm{CI} 1.47-5.88)$.

\section{Discussion}

There have been many studies demonstrating the effects of drug and alcohol use on sleep quality and sleep disorders, but few have examined the effects of psychological issues on sleep quality, especially in PLWH. Therefore, the present study has examined sleep quality and related factors among Iranian PLWH.

Based on PSQI results, 72\% of our participants had poor sleep quality. In studies conducted in Nigeria, Brazil, and Tehran, poor sleep quality was reported in $60 \%$, $47 \%$, and $47.5 \%$ of HIV patients, respectively $[4,15,16]$. These variations in the reported prevalence of sleep disturbance among PLWH across studies can be explained by study locations, participants' demographic characteristics, inclusion and exclusion criteria, or different tools used to collect data. 
Table 1 Sleep quality and its associations with other factors in Iranian PLWH

\begin{tabular}{|c|c|c|c|c|}
\hline \multirow[t]{2}{*}{ Variables } & \multirow{2}{*}{$\begin{array}{l}\text { Total }(n=304) \\
\text { Mean (SD) }\end{array}$} & \multirow{2}{*}{$\begin{array}{l}\text { Poor sleep quality } \\
(\mathrm{n}=219) \\
\text { Mean (SD) }\end{array}$} & \multirow{2}{*}{$\begin{array}{l}\text { Good sleep quality }(n=85) \\
\text { Mean (SD) }\end{array}$} & \multirow[t]{2}{*}{ P-value } \\
\hline & & & & \\
\hline Age, years (mean $\pm S D$ ) & $40.01(9.60)$ & $39.80(9.56)$ & $40.55(9.22)$ & 0.537 \\
\hline \multirow[t]{2}{*}{ BMI $\left(\mathrm{kg} / \mathrm{m}^{2}\right)$} & $43.75(24.73)$ & $24.55(4.15)$ & $25.19(3.90)$ & 0.216 \\
\hline & No (Percent) & No (Percent) & No (Percent) & \\
\hline \multicolumn{5}{|l|}{ Sex } \\
\hline Male & $209(68.8)$ & $151(68.9)$ & $58(68.2)$ & 0.904 \\
\hline Female & $95(31.3)$ & $68(31.1)$ & $27(31.8)$ & \\
\hline \multicolumn{5}{|l|}{ Marital status } \\
\hline Single $e^{a}$ & $149(49)$ & $106(48.4)$ & $43(50.6)$ & 0.732 \\
\hline Married (committed) & $155(51)$ & $113(51.6)$ & $42(49.4)$ & \\
\hline \multicolumn{5}{|l|}{ Education } \\
\hline Under diploma & $146(48)$ & $41(48.2)$ & $105(47.9)$ & 0.975 \\
\hline Diploma & $102(33.6)$ & $29(34.1)$ & $73(33.3)$ & \\
\hline Upper diploma & $56(18.6)$ & 15 (17.6) & $41(18.7)$ & \\
\hline \multicolumn{5}{|l|}{ Employment status } \\
\hline Employed & $218(71.7)$ & $146(66.7)$ & $72(84.7)$ & 0.002 \\
\hline Unemployed & $86(28.3)$ & 73 (33.3) & $13(15.3)$ & \\
\hline HIV characteristics & Mean (SD) & Mean (SD) & Mean (SD) & \\
\hline $\begin{array}{l}\text { Duration of HIV diagnosed, month (median, } \\
\text { IQR) }\end{array}$ & $50(63.75)$ & $62(62.5)$ & $49(64)$ & 0.073 \\
\hline Mean $\mathrm{CD} 4$ count (SD) & $577.12(301.21)$ & $580.60(318.35)$ & $568.15(253.26)$ & 0.747 \\
\hline \multirow[t]{2}{*}{ Duration of ART, years (Med, IQR) } & $40.00(46.75)$ & $47(47.5)$ & $38.00(44)$ & 0.241 \\
\hline & No (Percent) & No (Percent) & No (Percent) & \\
\hline \multicolumn{5}{|l|}{ CD4 count } \\
\hline$<500$ & $135(44.4)$ & $102(46.6)$ & $33(38.8)$ & 0.222 \\
\hline$\geq 500$ & $169(55.6)$ & $117(53.4)$ & $52(61.2)$ & \\
\hline \multicolumn{5}{|l|}{ Route of transmission } \\
\hline Sexual contact & $119(39.1)$ & $86(39.3)$ & $33(38.8)$ & 0.611 \\
\hline Injection drug use & $174(57.2)$ & $127(58)$ & $47(55.3)$ & \\
\hline Blood products & $4(1.3)$ & $2(0.9)$ & $2(2.4)$ & \\
\hline Unknown & $7(2.3)$ & $4(1.8)$ & $3(3.5)$ & \\
\hline HIV/HBV co-infection & $9(3)$ & $7(3.2)$ & $2(2.4)$ & 0.697 \\
\hline HIV/HCV co-infection & $69(22.7)$ & $51(23.3)$ & $18(21.2)$ & 0.693 \\
\hline HIV/TB co-infection & $28(9.2)$ & $23(10.5)$ & $5(5.9)$ & 0.211 \\
\hline
\end{tabular}

${ }^{a}$ Separated and divorced/widowed are in this category

We did not find any relationship between participants' gender, age, educational status, marital status, and BMI and their sleep quality, which contrasts with some other studies $[4,17,18]$. Some studies have shown an association between increased BMI and sleep disorders. In people with high BMI, abdominal obesity and difficulty achieving a comfortable sleeping position may contribute to poor sleep quality; however, the reason for this association remains unclear $[19,20]$. According to a Chinese study, sleep quality differed according to age, with younger individuals having more sleep disorders due to psychological issues [21].

Almost all components related to sleep quality were significantly different in people with good, and poor sleep quality, similar to previous studies as PLWH typically have sleep disturbances such as reduced sleep hours, waking up at night, and waking up early, overturning short brain waves, and rapid eye movements [22].

Stress negatively impacts sleep quality, as shown in the results. Psychological disorders such as stress and anxiety 
Table 2 Psychiatric and sleep characteristic of Iranian PLWH

\begin{tabular}{|c|c|c|c|c|}
\hline \multirow[t]{3}{*}{ Variables } & Total $(n=304)$ & Poor quality sleep $(n=219)$ & Good quality sleep $(n=85)$ & P-value \\
\hline & Mean (SD) & Mean (SD) & Mean (SD) & \\
\hline & No (percent) & No (percent) & No (percent) & \\
\hline \multicolumn{5}{|l|}{ Depression } \\
\hline Normal (0-9) & $135(44.4)$ & $81(37)$ & $54(63.5)$ & $<0.0001$ \\
\hline Mild (10-12) & $25(8.2)$ & $17(7.8)$ & $8(9.4)$ & \\
\hline Moderate (13-20) & $63(20.7)$ & $53(24.2)$ & $10(11.8)$ & \\
\hline Sever $(21-27)$ & $27(8.9)$ & $22(10)$ & $5(5.9)$ & \\
\hline Extremely severe (28-42) & $54(17.8)$ & $46(21)$ & $8(9.4)$ & \\
\hline \multicolumn{5}{|l|}{ Anxiety } \\
\hline Normal (0-6) & $152(50)$ & $91(41.6)$ & $61(71.8)$ & $<0.0001$ \\
\hline Mild (7-9) & $19(6.3)$ & $14(6.4)$ & $5(5.9)$ & \\
\hline Moderate (10-14) & $40(13.2)$ & $34(15.5)$ & $6(7.1)$ & \\
\hline Sever (15-19) & $31(10.2)$ & $27(12.3)$ & $4(4.7)$ & \\
\hline Extremely severe (20-42) & $62(20.4)$ & $53(24.2)$ & $9(10.6)$ & \\
\hline \multicolumn{5}{|l|}{ Stress } \\
\hline Normal (0-10) & 99 (32.6) & $49(22.4)$ & $50(58.8)$ & $<0.0001$ \\
\hline Mild (11-18) & $89(29.3)$ & $68(31.1)$ & $21(24.7)$ & \\
\hline Moderate (19-26) & $45(14.8)$ & $40(18.3)$ & $5(5.9)$ & \\
\hline Sever (27-34) & $37(12.2)$ & $33(15.1)$ & $4(4.7)$ & \\
\hline Extremely severe (35-42) & $34(11.2)$ & $29(13.2)$ & $5(5.9)$ & \\
\hline
\end{tabular}

Table 3 Results of the logistic regression model on the factors affecting the sleep quality in Iranian PLWH

\begin{tabular}{|c|c|c|c|c|}
\hline Variables & Crude OR & Cl 95\% (P-value) & Multivariate adjusted OR & $\mathrm{Cl}$ 95\% (P-value) \\
\hline Age, years (mean $\pm S D$ ) & $0.99(0.96-1.02)$ & 0.536 & $0.99(0.96-1.02)$ & 0.773 \\
\hline BMI & $0.96(0.90-1.02)$ & 0.216 & $1.01(0.93-1.07)$ & 0.973 \\
\hline Sex (female is reference) & $1.03(0.60-1.77)$ & 0.904 & $1.34(0.73-2.44)$ & 0.786 \\
\hline Marital status (single is reference) & $1.09(0.66-1.80)$ & 0.732 & $1.34(0.73-2.44)$ & 0.335 \\
\hline \multicolumn{5}{|l|}{ Education } \\
\hline Under diploma (reference) & 1 & & 1 & \\
\hline Diploma & $0.98(0.561-1.73)$ & 0.952 & $1.12(0.57-2.17)$ & 0.736 \\
\hline Upper diploma & $1.06(0.53-2.13)$ & 0.854 & $1.52(0.62-3.68)$ & 0.354 \\
\hline Employment status (Employed is reference) & $2.76(1.44-5.32)$ & 0.002 & $2.13(1.01-4.53)$ & 0.048 \\
\hline Duration of HIV diagnosed, month & $0.99(0.99-1.00)$ & 0.121 & $1.00(0.99-1.01)$ & 0.747 \\
\hline Duration of ART, years & $0.99(0.98-1.003)$ & 0.241 & $0.995(0.98-1.01)$ & 0.441 \\
\hline CD4 count $\geq 500$ (CD4 count $<500$ is reference) & $0.73(0.43-1.21)$ & 0.223 & $0.868(0.46-1.61)$ & 0.868 \\
\hline \multicolumn{5}{|l|}{ Route of transmission } \\
\hline Sexual contact (reference) & 1 & & 1 & \\
\hline Injection drug use & $1.25(0.65-2.27)$ & 0.197 & $1.19(0.50-2.17)$ & 0.295 \\
\hline Unknown or blood products & $1.17(0.62-1.60)$ & 0.225 & $1.72(0.40-3.21)$ & 0.935 \\
\hline HIV/HBV/TB coinfection ${ }^{\mathrm{a}}$ (Lack of coinfection is reference) & $1.15(0.65-2.03)$ & 0.615 & $0.970(0.46-2.01)$ & 0.970 \\
\hline Depression ${ }^{\mathrm{b}}$ (Lack of depression is reference) & $2.96(1.76-4.99)$ & $<0.0001$ & $1.26(0.61-2.67)$ & 0.537 \\
\hline Anxiety ${ }^{\mathrm{b}}$ (Lack of anxiety is reference) & $3.57(2.07-6.15)$ & $<0.0001$ & $1.52(0.68-3.43)$ & 0.314 \\
\hline Stress $^{\mathrm{b}}$ (Lack of stress is reference) & $4.95(2.89-8.47)$ & $<0.0001$ & $3.18(1.47-5.88)$ & 0.003 \\
\hline
\end{tabular}

Bold values indicate variables, which were statistically significant

${ }^{a} \mathrm{HIV} / \mathrm{HBV}$ or HIV/HCV or HIV/TB co-infection

${ }^{\mathrm{b}}$ Mild, moderate, severe, extremely severe were defined as abnormal 
are leading causes of insomnia among PLWH, and being stressed is more likely to result in difficulty sleeping [23]. Studies on the effects of stress on PLWH show associations between stress and anxiety, depression, sleep quality, and fatigue during the day [24, 25]. Many reasons contribute to HIV-related stress in patients, including fear of infecting others, revealing HIV status, job changes, interpersonal relationships, and changes in personal lives. Long-term stress can reduce their immunity and accelerate the progression of the disease. Providing social support to patients is a proven method of reducing stress and improving health, consequently improving quality of life [26].

In our study, employment status was an independent factor that affected sleep quality, and unemployed people were more likely to have poor sleep quality. Unemployment in PLWH and health-related characteristics were also associated with demographic and social factors, including younger age, lower levels of education, and the presence of stigma in the community [27, 28]. According to Jabbari et al., sleep quality among PLWH was influenced by occupational status and educational level [29]. Poverty is also a chronic stressor that can cause irreparable damage to a person's physical and mental health, affecting the quality of life, and consequently, sleep quality [30, 31].

\section{Conclusion}

Poor sleep quality seems to be a common issue caused by a variety of factors among PLWH. This group of people needs intervention to improve their sleep quality. Sleep disorders can also be treated with social support, such as finding a job, and non-pharmacological techniques such as sleep hygiene training, behavioral changes, and stress reduction activities.

\section{Limitations}

There are limitations to the present study that need to be addressed in future studies. The first limitation is that the participants were patients from VCT centers in Tehran and may not represent the entire population of Iranians with HIV. Furthermore, as we conducted a cross-sectional study, we could not evaluate the causal relationships between variables. In addition, measuring the quality of life of patients could provide more insight into the effect of sleep quality on people's lives, which was not investigated in this study.

\section{Abbreviations}

PLWH: People living with HIV; PSQI: Pittsburgh Sleep Quality Index; DASS:

Depression Anxiety Stress Scales; BMI: Body mass index.
Acknowledgements

We appreciate Tehran University of Medical Sciences (TUMS) to fund this study.

\section{Authors' contributions}

SA, MM and AN had the idea for this study. KSH, FA, ANA, collected the data. PAK, MB, SG wrote the article. FA, ANA, SS, and AJ revised the manuscript. All authors read and approved the final manuscript.

\section{Funding}

This study was funded by Tehran University of Medical Sciences (Grant number: 98-01-178-42140)

\section{Availability of data and materials}

The data that support the findings of this study are available from the corresponding author upon reasonable request.

\section{Declarations}

Ethics approval and consent to participate

We obtained written consent from participants prior to their participation in the study. The ethics committee of Tehran University of Medical Sciences approved the study protocol (Ethical code: IR.TUMS.VCR.REC.1398.312).

\section{Consent for publication}

Not applicable.

\section{Competing interests}

The authors declare that they have no known competing financial interests or personal relationships that could have influenced the work reported in this paper.

\section{Author details}

${ }^{1}$ Occupational Sleep Research Center, Baharloo Hospital, Tehran University of Medical Sciences, Tehran, Islamic Republic of Iran. ${ }^{2}$ Department of Epidemiology and Biostatistics, School of Public Health, Isfahan University of Medical Sciences, Isfahan, Iran. ${ }^{3}$ Research Development Center, Arash Women's Hospital, Tehran University of Medical Sciences, Tehran, Iran. ${ }^{4}$ Sports Medicine Research Center, Neuroscience Institute, Tehran University of Medical Sciences, Tehran, Iran. ${ }^{5}$ Department of Virology, School of Public Health, Tehran University of Medical Sciences, Tehran, Iran. ${ }^{6}$ Research Center for Clinical Virology, Tehran University of Medical Sciences, Tehran, Iran. ${ }^{7}$ Enter for Communicable Disease Control, Ministry of Health and Medical Education, Tehran, Iran. ${ }^{8} \mathrm{HIV}$ Expert of Deputy of Health, Tehran University of Medical Sciences, Tehran, Iran.

Received: 6 May 2021 Accepted: 20 August 2021

Published online: 30 August 2021

\section{References}

1. Sung JJ, Lau JY, Goh K, Leung W, Cancer APWGoC. Increasing incidence of colorectal cancer in Asia: implications for screening. Lancet Oncol. 2005;6(11):871-6.

2. Rueda S, Raboud J, Mustard C, Bayoumi A, Lavis JN, Rourke SB. Employment status is associated with both physical and mental health quality of life in people living with HIV. AIDS Care. 2011:23(4):435-43.

3. Chen WT, Lee SY, Shiu CS, Simoni JM, Pan C, Bao M, et al. Fatigue and sleep disturbance in HIV-positive women: a qualitative and biomedical approach. J Clin Nurs. 2013;22(9-10):1262-9.

4. Dabaghzadeh F, Khalili H, Ghaeli P, Alimadadi A. Sleep quality and its correlates in HIV positive patients who are candidates for initiation of antiretroviral therapy. Iran J Psychiatry. 2013;8(4):160-4.

5. George Dalmida S, McDonnell Holstad M, Fox R, Mara DA. Depressive symptoms and fatigue as mediators of relationship between poor sleep factors and medication adherence in HIV-positive women. J Res Nurs. 2015;20(6):499-514

6. Shohani MAS, Seidkhani H, Gholami Z. Assessing The Quality of Sleep in Iranian elderly people by the standard Pittsburgh Sleep Quality Index: 
systematic review and meta-analysis method. Indian J Forensic Med Toxicol. 2019;13(4):367-73.

7. Zamani A, Haghnegahdar A, Vossoughi M. Evaluation of association between the severity of temporomandibular disorders and quality of sleep in a selected Iranian population. Front Dent. 2019;16(3):206-13.

8. Sadeghniiat-Haghighi K, Yazdi Z, Kazemifar AM. Sleep quality in long haul truck drivers: a study on Iranian national data. Chin J Traumatol = Zhonghua chuang shang za zhi. 2016;19(4):225-8.

9. Habibi F, Mahdavi S, Khaniabadi B, Habibi M, Gharavinia A, Baghaei A, et al. Sleep quality and associated factors in Iranian inflammatory bowel disease patients. J Res Med Sci. 2019;24(1):59.

10. Mohammad Gholi Mezerji N, Naseri P, Omraninezhad Z, Shayan Z. The reliability and validity of the Persian Version of Pittsburgh Sleep Quality Index in Iranian people. Avicenna J Neuropsychophysiol. 2017:4(3):95-102.

11. Mollayeva T, Thurairajah P, Burton K, Mollayeva S, Shapiro CM, Colantonio A. The Pittsburgh sleep quality index as a screening tool for sleep dysfunction in clinical and non-clinical samples: a systematic review and meta-analysis. Sleep Med Rev. 2016;25:52-73.

12. Dreyer Z, Henn C, Hill C. Validation of the Depression Anxiety Stress Scale21 (DASS-21) in a non-clinical sample of South African working adults. J Psychol Afr. 2019;29(4):346-53.

13. Darchini-Maragheh E, Salehi M, Payandeh A, Behdani F, Ghasemzadeh $\mathrm{KH}$. Evaluation of the correlations between depression, anxiety, and stress as DASS-21 subscales and high-risk behaviors in the adolescents in Torghabeh and Shandiz Towns, Iran. J Patient Saf Qual Improv. 2017:5(3):584-90.

14. Asghari A, Saed F, Dibajnia P. Psychometric properties of the Depression Anxiety Stress Scales-21 (DASS-21) in a non-clinical Iranian sample. Int J Psychol (IPA). 2008;2(2):82-102.

15. Oshinaike O, Akinbami A, Ojelabi O, Dada A, Dosunmu A, John Olabode S. Quality of sleep in an HIV population on antiretroviral therapy at an Urban Tertiary Centre in Lagos, Nigeria. Neurol Res Int. 2014;2014:298703.

16. Ferreira LT, Ceolim MF. Sleep quality in HIV-positive outpatients. Revista da Escola de Enfermagem da U S P. 2012;46(4):892-9.

17. Allavena C, Guimard T, Billaud E, De la Tullaye S, Reliquet V, Pineau S, et al. Prevalence and risk factors of sleep disturbance in a large HIV-infected adult population. AIDS Behav. 2016;20(2):339-44.

18. Gutierrez J, Tedaldi EM, Armon C, Patel V, Hart R, Buchacz K. Sleep disturbances in HIV-infected patients associated with depression and high risk of obstructive sleep apnea. SAGE Open Med. 2019;7:2050312119842268.

19. Crum-Cianflone NF, Roediger MP, Moore DJ, Hale B, Weintrob A, Ganesan $A$, et al. Prevalence and factors associated with sleep disturbances among early-treated HIV-infected persons. Clin Infect Dis. 2012;54(10):1485-94.
20. Brown TT, Patil SP, Jacobson LP, Margolick JB, Laffan AM, Godfrey RJ, et al. Anthropometry in the prediction of sleep disordered breathing in HIVpositive and HIV-negative men. Antivir Ther. 2010;15(4):651-9.

21. Zhao $X$, Lan $M, L i H$, Yang J. Perceived stress and sleep quality among the non-diseased general public in China during the 2019 coronavirus disease: a moderated mediation model. Sleep Med. 2020;77:339-45.

22. Lee KA, Gay C, Portillo CJ, Coggins T, Davis H, Pullinger CR, et al. Types of sleep problems in adults living with HIV/AIDS. J Clin Sleep Med. 2012:8(1):67-75.

23. Huang X, Li H, Meyers K, Xia W, Meng Z, Li C, et al. Burden of sleep disturbances and associated risk factors: a cross-sectional survey among HIV-infected persons on antiretroviral therapy across China. Sci Rep. 2017;7(1):3657.

24. Hand GA, Phillips KD, Dudgeon WD. Perceived stress in HIV-infected individuals: physiological and psychological correlates. AIDS Care. 2006;18(8):1011-7.

25. Lee EH. Understanding the associations among depression, coping, social support, and perceived stress in adults living with HIV/AIDS: a path analysis. Palo Alto: Palo Alto University; 2018.

26. Hecht FM, Moskowitz JT, Moran P, Epel ES, Bacchetti P, Acree M, et al. A randomized, controlled trial of mindfulness-based stress reduction in HIV infection. Brain Behav Immun. 2018;73:331-9.

27. Tao J, Wang L, Kipp AM, Qian HZ, Yin L, Ruan Y, et al. Relationship of stigma and depression among newly HIV-diagnosed chinese men who have sex with men. AIDS Behav. 2017;21(1):292-9.

28. Groß M, Herr A, Hower M, Kuhlmann A, Mahlich J, Stoll M. Unemployment, health, and education of HIV-infected males in Germany. Int J Public Health. 2016;61 (5):593-602.

29. Jabbari F, Dabaghzadeh F, Khalili H, Abbasian L. Associated factors of sleep quality in HIV-positive individuals. Future Virol. 2015;10(2):89-96.

30. Hjelm L, Handa S, de Hoop J, Palermo T. Poverty and perceived stress: evidence from two unconditional cash transfer programs in Zambia. Soc Sci Med. 1982;2017(177):110-7.

31. Campbell R, Vansteenkiste M, Delesie L, Soenens B, Tobback E, Vogelaers $D$, et al. The role of basic psychological need satisfaction, sleep, and mindfulness in the health-related quality of life of people living with HIV. J Health Psychol. 2019;24(4):535-45.

\section{Publisher's Note}

Springer Nature remains neutral with regard to jurisdictional claims in published maps and institutional affiliations.

Ready to submit your research? Choose BMC and benefit from:

- fast, convenient online submission

- thorough peer review by experienced researchers in your field

- rapid publication on acceptance

- support for research data, including large and complex data types

- gold Open Access which fosters wider collaboration and increased citations

- maximum visibility for your research: over 100M website views per year

At BMC, research is always in progress.

Learn more biomedcentral.com/submissions 